Article

\title{
Dietary Zinc Deficiency Affects Blood Linoleic Acid: Dihomo- $\gamma$-linolenic Acid (LA:DGLA) Ratio; a Sensitive Physiological Marker of Zinc Status in Vivo (Gallus gallus)
}

\author{
Spenser Reed ${ }^{1,2}$, Xia Qin ${ }^{3}$, Rinat Ran-Ressler ${ }^{2, \dagger}$, James Thomas Brenna ${ }^{2}$, Raymond P. Glahn ${ }^{1}$ \\ and Elad Tako ${ }^{1, *}$
}

1 USDA-ARS, Robert Holley Center for Agriculture \& Health, Ithaca, NY 14853, USA;

E-Mails: smr292@ cornell.edu (S.R.); raymond.glahn@ars.usda.gov (R.P.G.)

2 Division of Nutritional Sciences, Cornell University, Ithaca, NY 14853, USA;

E-Mails: Rinat.Ran-Ressler@rd.nestle.com (R.R.-R.); jtb4@ cornell.edu (J.T.B.)

3 Department of Food Science, Cornell University, Ithaca, NY 14853, USA;

E-Mail: xq37@cornell.edu

† Present address: Nestlé R \& D Center Minneapolis, 12500 Whitewater Drive,

Minnetonka, MN 55343, USA.

* Author to whom correspondence should be addressed; E-Mail: et79@ cornell.edu;

Tel.: +1-607-255-5434; Fax: +1-607-255-1132.

Received: 9 January 2014; in revised form: 1 March 2014 / Accepted: 5 March 2014 /

Published: 20 March 2014

\begin{abstract}
Zinc is a vital micronutrient used for over 300 enzymatic reactions and multiple biochemical and structural processes in the body. To date, sensitive and specific biological markers of zinc status are still needed. The aim of this study was to evaluate Gallus gallus as an in vivo model in the context of assessing the sensitivity of a previously unexplored potential zinc biomarker, the erythrocyte linoleic acid: dihomo- $\gamma$-linolenic acid (LA:DGLA) ratio. Diets identical in composition were formulated and two groups of birds $(n=12)$ were randomly separated upon hatching into two diets, $\mathrm{Zn}(+)$ (zinc adequate control, $42.3 \mu \mathrm{g} / \mathrm{g}$ zinc), and $\mathrm{Zn}(-)$ (zinc deficient, $2.5 \mu \mathrm{g} / \mathrm{g}$ zinc). Dietary zinc intake, body weight, serum zinc, and the erythrocyte fatty acid profile were measured weekly. At the conclusion of the study, tissues were collected for gene expression analysis. Body weight, feed consumption, zinc intake, and serum zinc were higher in the $\mathrm{Zn}(+)$ control versus $\mathrm{Zn}(-)$ group $(p<0.05)$. Hepatic TNF- $\alpha$, IL-1 $\beta$, and IL-6 gene expression were higher in the $\mathrm{Zn}(+)$ control group $(p<0.05)$, and hepatic $\Delta^{6}$ desaturase was significantly higher in the $\mathrm{Zn}(+)$ group
\end{abstract}


$(p<0.001)$. The LA:DGLA ratio was significantly elevated in the $\mathrm{Zn}(-)$ group compared to the $\mathrm{Zn}(+)$ group $(22.6 \pm 0.5$ and $18.5 \pm 0.5, \% \mathrm{w} / \mathrm{w}$, respectively, $p<0.001)$. This study suggests erythrocyte LA:DGLA is able to differentiate zinc status between zinc adequate and zinc deficient birds, and may be a sensitive biomarker to assess dietary zinc manipulation.

Keywords: zinc; zinc deficiency; zinc biomarker; broiler chicken; $\Delta^{6}$ desaturase; delta-6 desaturase; red blood cell fatty acids

\section{Introduction}

Zinc is one of the most abundant trace minerals in cells, and is essential for growth and development of nearly all organisms [1]. With 1.5-2.5 g of zinc present in the average adult [2], zinc is second only to iron in total body trace mineral content. It is found primarily in tissues such as the brain, kidneys, pancreas and liver with smaller concentrations in hair, skin and fingernails [3]. Zinc is vital for numerous physiological and metabolic processes, such as acting as an antioxidant and cofactor in over 300 zinc metalloenzymes [4,5]. Zinc functions in the regulation of an extensive variety of genes such as those involved in nucleic acid metabolism [6], cell signaling [7,8], and apoptosis [9]. Zinc also plays an integral role in immune system functioning [10-13]. Since there is no readily-accessible storage form of zinc, regulation is highly efficient [14-16]. In humans, tight regulation is accomplished by the control of zinc absorption and transport to and from the small intestine via two families of transmembrane proteins [17-21], solute carrier 30A (Slc30a, ZnT) and Slc39a members (ZIP). As was previously demonstrated, expression of several of these proteins is usually upregulated in zinc deficiency conditions [17].

However, despite an increasing understanding of zinc homeostasis, the paucity of sensitive zinc biomarkers, as well as a representative animal model in which to test them, has made assessment of zinc deficiency difficult to both quantify and categorize. Although whole blood, plasma, and urine zinc decrease in severe zinc deficiency, accurate assessment of zinc status, especially in mild to moderate deficiency, is difficult as studies with these biomarkers are often contradictory and inconsistent. In their recent meta-analysis on biological indicators of zinc status, Lowe et al. concluded plasma, serum, urinary, and hair zinc were the only effective biological indicators out of 32 potential biomarkers from 46 publications in humans [22]. Previous studies have shown plasma and serum zinc to be insensitive indicators of zinc status [23-25], although some studies demonstrate they respond to both depletion and repletion of zinc [26,27]. Erythrocyte zinc is often used to evaluate zinc status, although this biomarker has been shown to be both responsive [25] and non-responsive [26] to zinc depletion. Further, purported biomarkers such as hair [26], urinary [25], and fecal zinc [22] have shown mixed efficacy as sensitive biomarkers of zinc status during dietary intervention; these discrepancies may be independent of differences in experimental protocol. The need to develop additional robust indicators of zinc status and expound upon the already known clinical markers, for which limited data of reliability exists, is evident. 
The broiler chicken (Gallus gallus) matures relatively quickly and is sensitive to dietary manipulation of various micronutrients such as zinc [28-31]. As was previously demonstrated [32-35], the broiler chicken is a responsive model in which to test dietary iron bioavailability. Further studies have shown the broiler chicken highly sensitive to dietary zinc manipulation [28-35]. Also, it was previously demonstrated that birds have a similar membrane fatty acid composition to mammals [36], which makes it a potentially-ideal animal model to study essential fatty acid (EFA) accumulation in relation to mineral nutrition.

Using this animal model, we identified and implemented a previously unexplored biomarker of zinc status pertaining to erythrocyte $\Delta^{6}$ desaturation. The physiology of membrane fatty acid accumulation in relation to zinc homeostasis has been the subject of little investigation in the literature, even though zinc plays a crucial role as a cofactor for the desaturase enzymes [37,38]. Initial studies proposed a role for zinc and EFAs in swine parakeratosis [39]. Bettger et al. later suggested a physiological connection between zinc and EFAs, as zinc deficiency increased proportions of arachidonic acid (20:406) [40]. Horrobin et al. postulated that desaturase enzymes require zinc as a cofactor for proper functioning [38]. Desaturase enzymes have both a requirement for zinc and a relatively low binding constant $[41,42]$, thus their activity is quite sensitive to early-stage zinc deficiency. What ensues is a disturbed ratio of

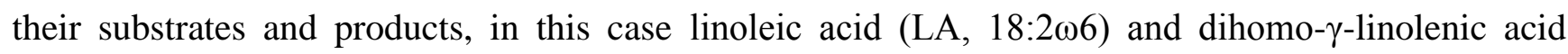

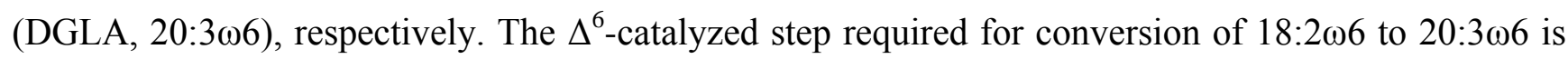

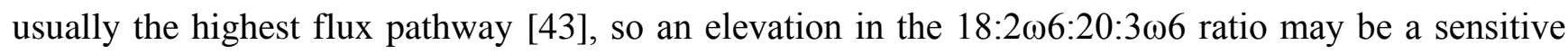
marker for zinc deficiency.

It is known [37] that, because of the zinc requirement of $\Delta^{6}$ desaturase, increasing dietary

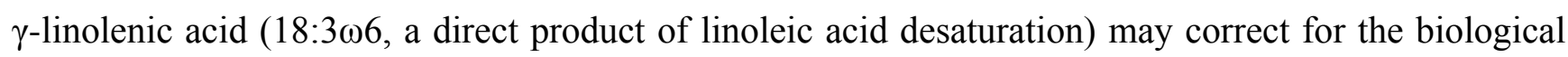
effects of zinc deficiency in terms of membrane EFA composition. Similarly, increasing dietary concentrations of LA may modify the LA:DGLA ratio independent of zinc status. Therefore, the knowledge of and/or controlling for dietary concentration of both fatty acids may be important in qualifying the specificity of the LA:DGLA biomarker. Thus, we investigated whether the ratio of 18:2 $\omega 6: 20: 3 \omega 6$ could be implemented as a sensitive biomarker of zinc status in vivo during the length of a controlled feeding trial. Also, hepatic mRNA gene expression for the $\Delta^{6}$ desaturase enzyme was measured. Figure 1 represents the role zinc plays in the rate-limiting desaturase step of the $\omega 6$ fatty acid pathway.

To provide context in determining the sensitivity of the LA:DGLA biomarker, we also assessed several relevant zinc-dependent factors, such as the expression of zinc transporter proteins (ZnT1, ZnT5, ZnT7, ZIP6, ZIP9, and DMT-1), immunomodulatory cytokines (TNF- $\alpha$, IL-1 $\beta$, IL-6), a transcription factor $(\mathrm{NF}-\kappa \mathrm{B})$, zinc-dependent digestive (AP and SI) and metabolically-relevant $\left(\mathrm{Na}^{+} \mathrm{K}^{+}\right.$ATPase and SGLT-1) enzymes, a zinc binding protein (MT4), as well as physiological markers (body weight, feather, nail, and serum zinc).

We hypothesize that the LA:DGLA biomarker assessed in this study will respond to changing levels of dietary zinc. Such a biomarker could be used to rapidly screen zinc status in vivo. Therefore, the primary objective of this study was to evaluate the response of the LA:DGLA ratio, as well as other indices of zinc nutriture, to dietary zinc deficiency in the Gallus gallus model. This study reports on the initial findings of the development and implementation of the LA:DGLA biomarker. 
Figure 1. A truncated schematic of the LA to DGLA fatty acid pathway within the erythrocyte membrane. Lack of dietary zinc (broken line), needed for $\Delta^{6}$ desaturase enzyme function, will impede conversion of reactant (LA) to product (DGLA) and will result in an increased ratio of LA to DGLA. This ratio may be a sensitive biomarker to identify endogenous zinc deficiency.

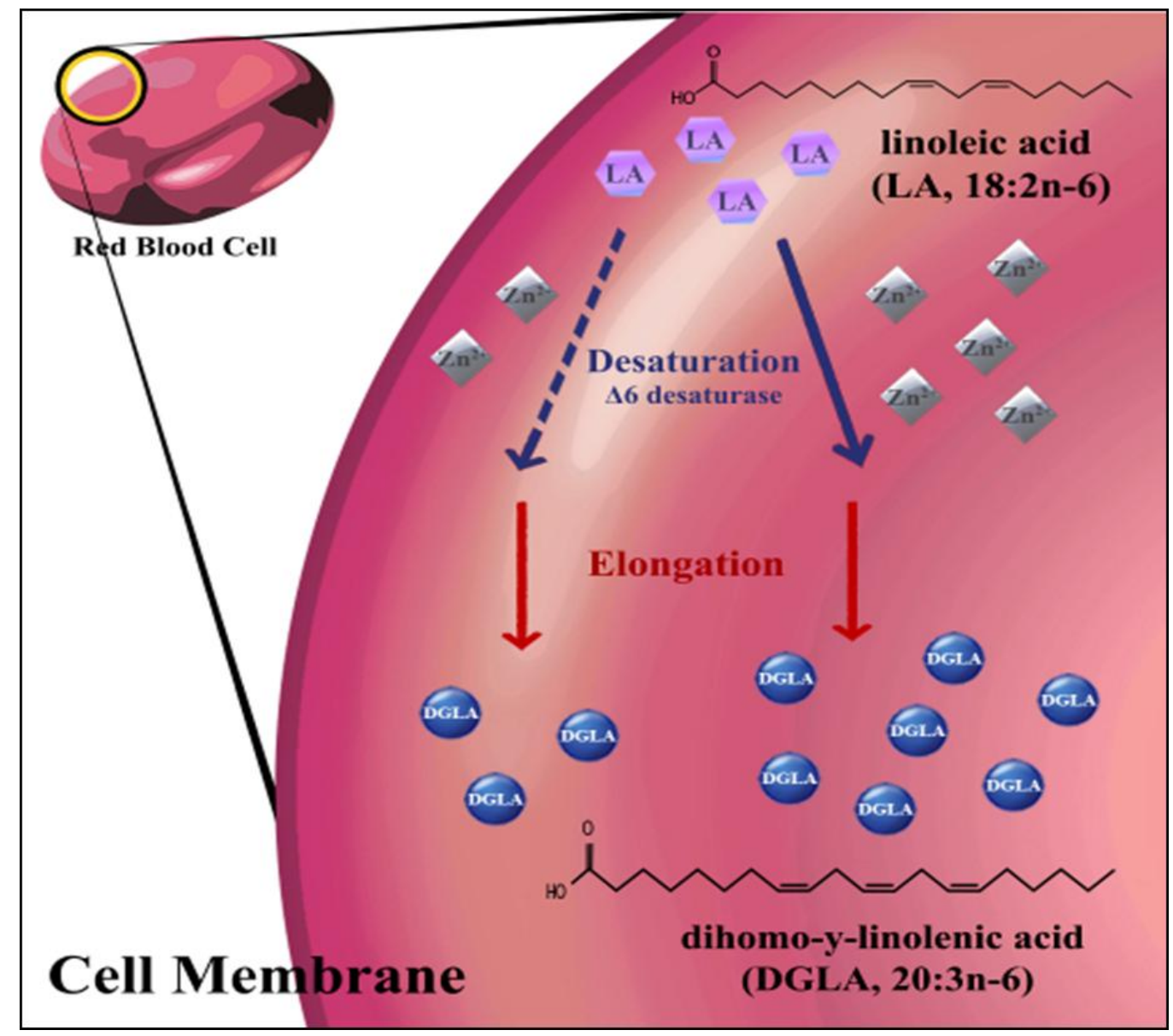

\section{Experimental Section}

\subsection{Animals, Diets and Study Design}

Forty-eight Cornish cross-fertile broiler eggs were obtained from a commercial hatchery (Moyer's Chicks, Quakertown, PA, USA). The eggs were incubated under optimal conditions at the Cornell University Animal Science Poultry Farm incubator. Upon hatching (hatchability rate was 94\%), chicks were randomly allocated into two treatment groups on the basis of body weight and gender (aimed to ensure equal distribution between groups, $n=12)$ : (1) Zinc adequate control diet ( $\mathrm{Zn}(+), 42.29 \mu \mathrm{g} / \mathrm{g}$ zinc); and (2) Zinc deficient diet ( $\mathrm{Zn}(-), 2.55 \mu \mathrm{g} / \mathrm{g}$ zinc). Experimental diets differed only on the basis of supplemental zinc (as zinc carbonate). Table 1 represents the two diets. Table 2 represents the fatty acid composition of the two diets. Chicks were housed in a total-confinement building (one chick per $0.5 \mathrm{~m}^{2}$ metal cage). Birds were under indoor controlled temperatures and were provided $16 \mathrm{~h}$ of light. All birds were given ad libitum access to purified water and food. Feed intakes were measured daily (as from day one), and body weight was measured weekly. 
Table 1. Composition of the experimental diets *.

\begin{tabular}{ccc}
\hline Ingredient & $\mathbf{Z n ( + )}$ Control Diet & $\mathbf{Z n}(-)$ Diet \\
\hline & g/kg (by Formulation) & \\
\hline Egg whites & 200 & 200 \\
DL-Methionine & 3 & 3 \\
Cornstarch & 318.2 & 318.2 \\
Dyetrose & 105 & 105 \\
Dextrose & 200.0 & 190.8 \\
Cellulose & 50 & 50 \\
Corn oil & 50 & 50 \\
Salt mix (no Zn) & 60 & 60 \\
Vitamin mix & 10 & 10 \\
Biotin (1 mg/g) & 1.8 & 1.8 \\
Choline bitartrate & 2 & 2 \\
Zinc carbonate (5 mg/g) & 9.2 & - \\
Total (g) & 1000 & 1000 \\
\hline
\end{tabular}

Concentrations of Selected Components (means \pm SEM, $n=5$ )

$\begin{array}{ccc}\text { Zinc concentration }(\mathrm{ppm}) * * & 42.29^{\mathrm{a}} \pm 0.25 & 2.55^{\mathrm{b}} \pm 0.02 \\ \text { Iron concentration }(\mathrm{ppm}) & 98.75 \pm 2.04 & 102.19 \pm 5.21 \\ \text { Phytic acid } * * * & <\mathrm{dL} & <\mathrm{dL}\end{array}$

* Modified NRC [44] purified chicken diets were provided by Dyets Inc. (Bethlehem, PA, USA), (Zn(+), Zn adequate control diet: 135251, $\mathrm{Zn}(-), \mathrm{Zn}$ deficient diet: 135252). ** Determination of zinc concentration is described in the materials and methods section. *** Determination of phytic acid in the diet is described in the Materials and Methods sections. Values are below the detection limit (dL). ${ }^{\text {a,b }}$ Within a column, means without a common letter are significantly different $(p<0.05)$.

Table 2. Fatty acid composition of the $\mathrm{Zn}(+)$ control and $\mathrm{Zn}(-)$ diets $* * * *$

\begin{tabular}{ccc}
\hline Fatty Acid & Zn(+) Control Diet $(\%$ w/w $)$ & Zn(-) Diet $(\%$ w/w $)$ \\
\hline $16: 0$ & $11.20 \pm 0.11$ & $11.57 \pm 0.34$ \\
$16: 1$ & $0.17 \pm 0.01$ & $0.18 \pm 0.02$ \\
$17: 0$ & $0.10 \pm 0.01$ & $0.11 \pm 0.04$ \\
$17: 1$ & $0.08 \pm 0.03$ & $0.07 \pm 0.01$ \\
$18: 0$ & $2.26 \pm 0.04$ & $2.31 \pm 0.05$ \\
$18: 1 n-9$ & $28.31 \pm 0.15$ & $28.42 \pm 0.16$ \\
$18: 2 n-6$ & $55.55 \pm 0.22$ & $55.19 \pm 0.18$ \\
$18: 3 n-3$ & $1.25 \pm 0.03$ & $1.28 \pm 0.02$ \\
$20: 3 n-6$ & $0.49 \pm 0.06$ & $0.43 \pm 0.01$ \\
$20: 1 n-9$ & $0.41 \pm 0.01$ & $0.42 \pm 0.02$ \\
\hline
\end{tabular}

* Modified NRC [44] purified chicken diets were provided by Dyets Inc. (Bethlehem, PA, USA), (Zn(+), Zn adequate control diet: $135251, \mathrm{Zn}(-)$, Zn deficient diet: 135252).** Determination of dietary fatty acid composition is described in the Materials and Methods section.

Zinc intakes were calculated from feed intakes and zinc concentration in the diets. At the end of the study (day 28), birds were euthanized by carbon dioxide exposure. The digestive tracts (colon and small intestine) and liver were quickly removed from the carcass and separated into various sections for tissue analysis ( 1-2 cm; 2-3 g was taken from small intestine and liver, respectively). The samples were immediately frozen in liquid nitrogen, and then stored in a $-80{ }^{\circ} \mathrm{C}$ freezer until 
analysis. All animal protocols were approved by the Cornell University Institutional Animal Care and Use committee.

\subsection{Determination of Serum, Nail and Feather Zinc Content}

Blood samples were collected weekly from the wing vein $(n=12, \sim 100 \mu \mathrm{L})$ using micro-hematocrit heparinized capillary tubes (Fisher Scientific, Pittsburgh, PA, USA). Samples were collected in the morning following an $8 \mathrm{~h}$ overnight fast. Nail and feather samples were collected on day 28 of the experiment ( $n=12, \sim 1-2 \mathrm{~g}$ ). Serum, nail and feather zinc concentrations were determined by an inductively-coupled argon-plasma/atomic emission spectrophotometer (ICAP 61E Thermal Jarrell Ash Trace Analyzer, Jarrell Ash Co., Franklin, MA, USA) following wet ashing.

\subsection{Isolation of Total RNA}

Total RNA was extracted from $30 \mathrm{mg}$ of duodenal (proximal duodenum, $n=9$ ) and liver tissues ( $n=9$ ) using Qiagen RNeasy Mini Kit (Qiagen Inc., Valencia, CA, USA) according to the manufacturer's protocol. All steps were carried out under RNase free conditions. RNA was quantified by absorbance at $260-280 \mathrm{~nm}$. Integrity of the $28 \mathrm{~S}$ and $18 \mathrm{~S}$ rRNA was verified by $1.5 \%$ agarose gel electrophoresis followed by ethidium bromide staining.

\subsection{Gene Expression Analysis}

As previously described [45-48], PCR was carried out with primers chosen from the fragments of chicken duodenal and hepatic tissues. Tissue-specific 18S rRNA was used to normalize the results. All PCR products were separated by electrophoresis on $2 \%$ agarose gels, stained with ethidium bromide, and quantified using the Quantity One 1-D analysis software (Bio-Rad, Hercules, CA, USA). Table 3 represents the totality of genes assessed in this study.

\subsection{Fatty Acid Analysis of Erythrocytes and Experimental Diets}

Blood samples were centrifuged at $2000 \mathrm{~g}$ for $10-15 \mathrm{~min}$ at room temperature to fractionate whole blood. Total lipids were then extracted from red blood cells and experimental diets according to a modified Bligh and Dyer method [49]. Fatty acid methyl esters (FAMEs) were prepared using 14\% boron trifluoride in methanol (Sigma Chemical, St. Louis, MO, USA). Butylated hydroxytoluene was added to methanol as an antioxidant. Heptadecanoic acid (Sigma Chemical, St Louis, MO, USA) in chloroform was used as an internal standard. FAME analyses were performed using a Hewlett Packard 5890 Gas Chromatograph (GC) (GMI Inc., Ramsey, MN, USA) with a flame ionization detector (FID) (GMI Inc., Ramsey, MN, USA). A BPX-70 column $(25 \mathrm{~m} \times 0.22 \mathrm{~mm} \times 0.25 \mu \mathrm{m}$, SGE, Austin, TX, USA) was used for the analysis with $\mathrm{H}_{2}$ as the carrier gas. FAME identities were determined by a chemical ionization (CI) mass spectrometry (MS), using a Varian Star 3400 GC (Varian Inc., Walnut Creek, CA, USA) coupled to a Varian Saturn 2000 Ion Trap MS (Varian Inc., Walnut Creek, CA, USA). FAME identities were based on GC retention time of each substance and its CI mass spectra. An equal weight FAME mixture (68A; Nuchek Prep, Elysian, MN, USA) was used to calculate response factors. Fatty acid (FA) levels are expressed as weight $\%$ of total FA (\% w/w). 
Table 3. Measured genes (Gallus gallus) and tissue-specific 18S rRNA from mRNA.

\begin{tabular}{|c|c|c|c|c|c|}
\hline \multirow[t]{2}{*}{ Analyte } & \multirow[t]{2}{*}{ Organ } & \multirow{2}{*}{$\begin{array}{c}\text { Forward Primer }\left(5^{\prime} \rightarrow 3^{\prime}\right) \\
\text { (Nucleotide Position) }\end{array}$} & \multirow{2}{*}{$\begin{array}{c}\text { Reverse Primer }\left(5^{\prime} \rightarrow 3^{\prime}\right) \\
\text { (Nucleotide Position) }\end{array}$} & Length & $\begin{array}{c}\text { GI } \\
\text { Identifier }\end{array}$ \\
\hline & & & & \multicolumn{2}{|c|}{ (Base Pairs) } \\
\hline ZnT1 & Intestine & CCTCCAGACAACCTTTGGTG (64-83) & TACTGATCTGCAAACCTTGCCA (133-112) & 69 & 54109718 \\
\hline ZnT5 & Intestine & TCGTGGAGGCTGTCATTCAC (1657-1676) & TGCAGATCTTTCTCCTGTTCGT (2016-1995) & 359 & 56555150 \\
\hline $\mathrm{ZnT7}$ & Intestine & GGCGTCTGGAGTAACAGCTT (166-185) & GTGAATGCCCATGACCTCCA (502-483) & 336 & 56555152 \\
\hline ZIP6 & Intestine & TTGTGGAATCATCCCAGGGC (549-568) & GCTCATTCGCATCTCTCCGA (929-909) & 380 & 66735072 \\
\hline ZIP9 & Intestine & TTATTCCCCTGGCCGTGAAC (68-87) & CCAATGCGAAGACCAGCAAG (643-624) & 575 & 237874618 \\
\hline TNF- $\alpha$ & Liver & CATTTGGAAGCAGCGTTCGG (48-67) & GACAGGGTAGGGGTGAGGAT (249-230) & 202 & 53854909 \\
\hline IL-1 $\beta$ & Liver & CCTCCAGCCAGAAAGTGAGG (431-450) & TTGTAGCCCTTGATGCCCAG (539-520) & 109 & 88702685 \\
\hline IL-6 & Liver & AACAACCTCAACCTGCCCAA (338-357) & AGGTCTGAAAGGCGAACAGG (449-430) & 112 & 302315692 \\
\hline$N F-\kappa B$ & Liver & GGATGGTCTGTTCCTGAAGA (1682-1702) & ACCTCTGCCTGCTTTGTGAT (1981-1961) & 300 & 2130627 \\
\hline AP & Intestine & GAATGAGGGCTTTGCCTCCT (1245-1264) & GAAGTTGCTGTTGGTGGCTG (1854-1835) & 610 & 45382360 \\
\hline SI & Intestine & CAGATCTCAGCCCGTCTTCC (237-256) & CCAGAATGCCACCGGTAACT (519-500) & 282 & 2246388 \\
\hline $\begin{array}{c}\mathrm{Na}+\mathrm{K}+ \\
\text { ATPase }\end{array}$ & Intestine & CTGAGGGCAACGAAACAGTG (104-123) & ATCCCTCGGGTTGACCTCC (177-159) & 74 & 14330321 \\
\hline SGLT-1 & Intestine & GTGGAATGCCTTGGAGGGTA (3-22) & GCTTCCTCAGATACTCCGGC (123-104) & 121 & 8346783 \\
\hline MT4 & Intestine & ACCCGAACTGAACCATGGAC (36-55) & TTTTCGTGGTCCCTGTCACC (312-293) & 277 & 46048710 \\
\hline$\Delta^{6}$ desaturase & Liver & ACATGAACAGAGGAAGCGGG (780-799) & TCTGGATCTCCTCCCAGGTG (1754-1735) & 975 & 261865208 \\
\hline DMT-1 & Intestine & TTCCTCCTCAACAACGTCGG (1755-1774) & TCCCAATGCCATCCCAGTTC (1908-1889) & 154 & 206597489 \\
\hline 18S rRNA & Intestine, Liver & CGATGCTCTTAACTGAGT (1251-1269) & CAGCTTTGCAACCATACTC (1550-1531) & 300 & 7262899 \\
\hline
\end{tabular}




\subsection{Determination of Phytic Acid Concentration in the Diet Samples}

Dietary phytic acid (phytate)/total phosphorus was measured as phosphorus released by phytase and alkaline phosphatase, following the kit manufacturer's instructions (five replicates per diet). The total phosphate released is measured using a modified colorimetric method and given as grams phosphorus per $100 \mathrm{~g}$ of sample material (K-PHYT 12/12, Magazyme International, Bray, Ireland).

\subsection{Statistical Analysis}

Results were analyzed by ANOVA using the general linear models procedure of JMP software (SAS Institute Inc., Cary, NC, USA). Differences between treatments were compared by Tukey's test and values were considered statistically different at $p<0.05$. Mixed effect model test between serum zinc (fixed effect) and bird group (random effect) was performed to elucidate a possible correlation between serum $\mathrm{Zn}$ and LA:DGLA ratio. The data are presented as least square means with their standard error of the mean.

\section{Results}

Diets were similar in all 16 to 20 carbon fatty acids (three replicates per diet, Table 2). Further, both the zinc adequeate and zinc deficient diets contained no detectable amounts of phytic acid (five replicates per diet, Table 1, kit detection limit $40 \mathrm{mg}$ phytic acid/100 g sample).

Body weight, feed consumption, and zinc intake were consistently higher in the $\mathrm{Zn}(+)$ versus $\mathrm{Zn}(-)$ birds on days $7,14,21$, and $28(n=12, p<0.05$, Table 4$)$. Further, at each time point, serum zinc concentration for the $\mathrm{Zn}(+)$ control bird group was significantly higher than the $\mathrm{Zn}(-)$ bird group $(n=12, p<0.05$, Table 4).

Zinc concentration in both tissues (nail and feather) were increased in the $\mathrm{Zn}(+)$ group versus the $\mathrm{Zn}(-)$ group (day 28, $n=12, p<0.05$, Figure 2). Gene expression analysis of the intestinal tissue, with results reported relative to $18 \mathrm{~S}$ rRNA, revealed a higher mean (AU) for TNF- $\alpha$, IL-1 $\beta$, and IL-6 in the $\mathrm{Zn}(+)$ versus $\mathrm{Zn}(-)$ group $(n=9, p<0.05)$. Analysis of hepatic tissue for $\Delta^{6}$ desaturase relative to hepatic 18S rRNA showed significant differences between groups $(n=9, p<0.001)$, with a higher mean (AU) value for $\mathrm{Zn}(+)$ versus $\mathrm{Zn}(-)$ group. No other assessed parameter (zinc and metal transporters: ZnT1, ZnT5, ZnT7, ZIP6, ZIP9, DMT-1; transcription factor: NF-кB; brush border enzymes: aminopeptidase, sucrase-isomaltase, $\mathrm{Na}^{+} \mathrm{K}^{+}$ATPase, SGLT-1; binding protein: MT4) was significantly different between the $\mathrm{Zn}(+)$ and $\mathrm{Zn}(-)$ groups $(n=9, p>0.05$, Figure 3A shows gene expression, Figure 3B shows mean difference per treatment).

As for the LA:DGLA biomarker, the $\% \mathrm{w} / \mathrm{w}$ ratio was significantly elevated $(n=12, p<0.05)$ in the $\mathrm{Zn}(-)$ group on days 7,14 , and 21 but not significantly different on day 28 ( $p=0.0588)$ (Figure 4A). Overall, the biomarker was significantly different in reporting cumulative $\% \mathrm{w} / \mathrm{w}$ LA:DGLA ratio between the two groups, with the $\mathrm{Zn}(-)$ having a higher mean ratio $(n=12$, $p<0.001$, Figure 4B). The mixed effect model indicated a slight inverse trend between serum zinc and LA:DGLA ( $m=-0.18, t$-ratio $=-0.16$ on 40.28 degrees of freedom, $p=0.1349$ ). 
Table 4. Body weight, feed consumption, zinc intake, and serum zinc concentrations in chickens fed a $\mathrm{Zn}(+)$ control and $\mathrm{Zn}(-)$ diets from day 0 to $28 *$.

\begin{tabular}{|c|c|c|c|c|c|}
\hline Treatment & Day 0 & Day 7 & Day 14 & Day 21 & Day 28 \\
\hline \multicolumn{6}{|c|}{ Body weight (g) } \\
\hline $\mathrm{Zn}(+)$ & $39.5^{\mathrm{a}} \pm 1.1$ & $83.3^{\mathrm{a}} \pm 2.7$ & $154.6^{\mathrm{a}} \pm 8.9$ & $293.1^{\mathrm{a}} \pm 24.9$ & $482.5^{\mathrm{a}} \pm 44.2$ \\
\hline $\mathrm{Zn}(-)$ & $38.8^{\mathrm{a}} \pm 1.2$ & $72.1^{b} \pm 2.7$ & $106.9^{b} \pm 5.3$ & $132.8^{\mathrm{b}} \pm 6.6$ & $147.7^{\mathrm{b}} \pm 14.4$ \\
\hline \multicolumn{5}{|l|}{ Feed } & consumption \\
\hline \multicolumn{6}{|l|}{$(\mathrm{kg} /$ day $) * *$} \\
\hline $\mathrm{Zn}(+)$ & - & $0.152^{a} \pm 0.007$ & $0.194^{\mathrm{a}} \pm 0.009$ & $0.253^{a} \pm 0.013$ & $0.329^{\mathrm{a}} \pm 0.016$ \\
\hline $\mathrm{Zn}(-)$ & - & $0.131^{\mathrm{b}} \pm 0.007$ & $0.143^{b} \pm 0.007$ & $0.130^{b} \pm 0.007$ & $0.122^{b} \pm 0.006$ \\
\hline \multicolumn{6}{|l|}{ Zinc } \\
\hline \multicolumn{6}{|l|}{ intake $(\mathrm{g}) * * *$} \\
\hline $\mathrm{Zn}(+)$ & - & $7.4^{\mathrm{a}} \pm 0.5$ & $19.1^{\mathrm{a}} \pm 0.95$ & $37.2^{\mathrm{a}} \pm 1.9$ & $64.6^{\mathrm{a}} \pm 3.2$ \\
\hline $\mathrm{Zn}(-)$ & - & $0.40^{b} \pm 0.03$ & $0.84^{b} \pm 0.04$ & $1.1^{b} \pm 0.06$ & $1.4^{\mathrm{b}} \pm 0.07$ \\
\hline \multicolumn{6}{|l|}{$\begin{array}{l}\text { Serum zinc } \\
\text { concentration }\end{array}$} \\
\hline \multicolumn{6}{|l|}{$(\mu \mathrm{g} / \mathrm{g})$} \\
\hline $\mathrm{Zn}(+)$ & - & $3.42^{\mathrm{a}} \pm 0.19$ & $4.66^{\mathrm{a}} \pm 0.35$ & $4.73^{\mathrm{a}} \pm 0.25$ & $4.49^{\mathrm{a}} \pm 0.23$ \\
\hline $\mathrm{Zn}(-)$ & - & $2.87^{b} \pm 0.17$ & $3.59^{b} \pm 0.21$ & $3.45^{b} \pm 0.11$ & $3.39^{b} \pm 0.11$ \\
\hline
\end{tabular}

* Values are means \pm SEM. ** Values are mean daily feed intakes for the seven days preceding the day designated in the column heading. *** Values are cumulative weekly from day $0 .{ }^{\mathrm{a}, \mathrm{b}}$ Within a column and for each parameter, means without a common letter are significantly different $(n=12, p<0.05)$.

Figure 2. Chicken feather and nail zinc concentrations (day 28). ${ }^{\mathrm{a}, \mathrm{b}}$ Within each parameter, means without a common letter are statistically significant (means \pm SEM, $n=12$, $p<0.05)$.

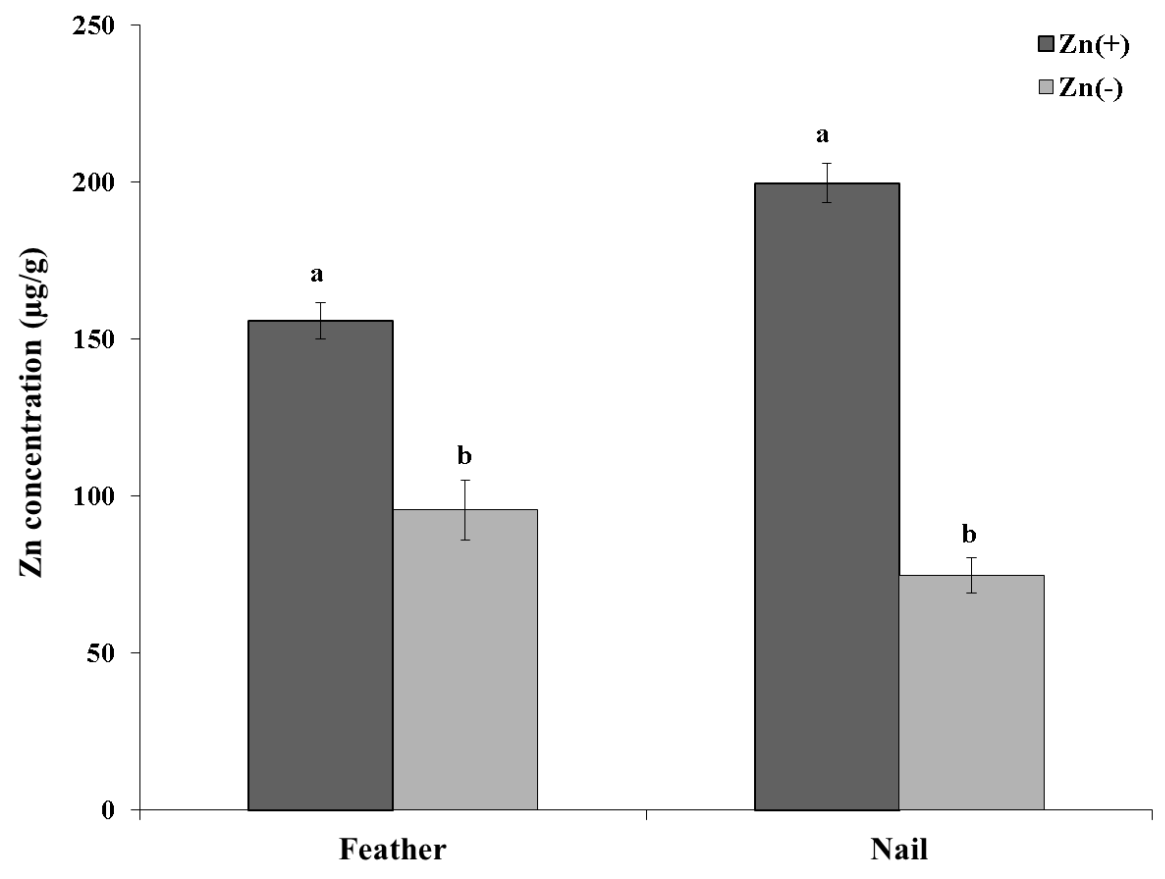


Figure 3. Intestinal (duodenal) and hepatic mRNA expression of zinc-related genes (day 28); changes in mRNA expression are shown relative to expression of 18S rRNA in arbitrary units (AU, $n=9$ ). (A) Effect of zinc deficiency on gene expression. Treatment groups are represented as $\mathrm{Zn}(+)$ control: birds $1-9$, and $\mathrm{Zn}(-)$ : birds 10-18. Treatment groups are represented on the $y$-axis, and zinc related genes on the $x$-axis. (B) Mean effect of zinc deficiency on gene expression $(* p<0.05$, ** $p<0.001)$.

(A)

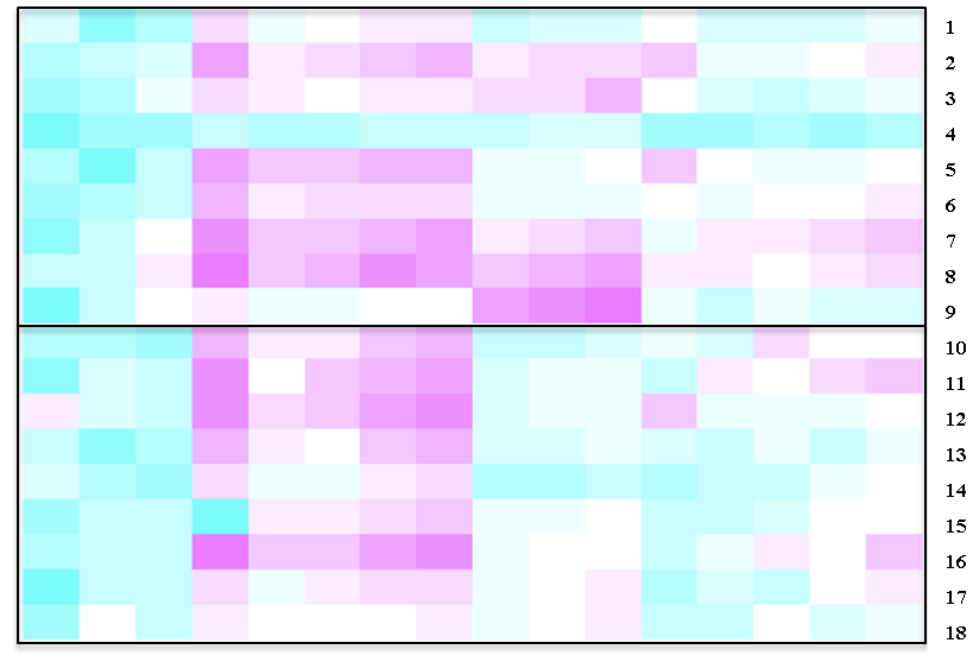

Zn (+)

$\operatorname{Zn}(-)$

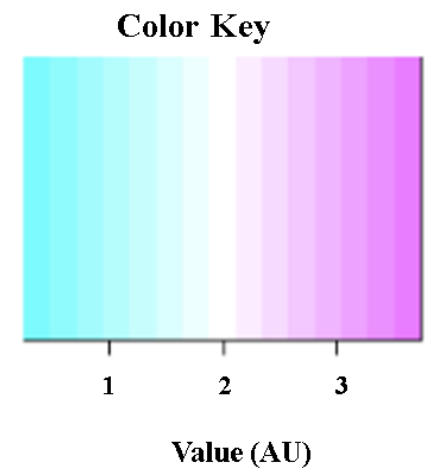

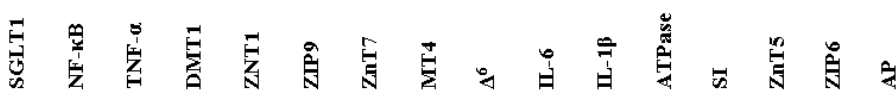

(B)

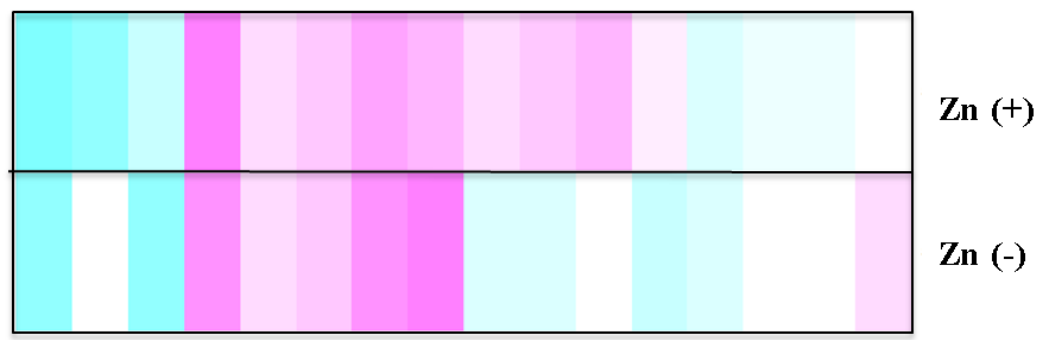

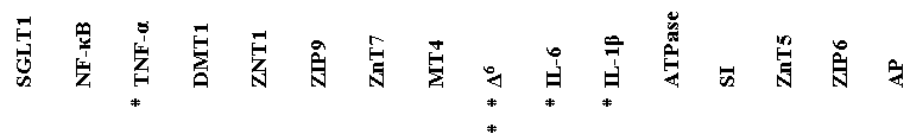

\section{Discussion}

This study represents the initial steps in evaluating the LA:DGLA ratio as a biomarker of zinc status in vivo. Previously, the broiler chicken has been used for nutritional research and has been shown to be an accurate animal to use in iron bioavailability studies, as chicks respond quickly to malnutrition, and their micronutrient deficient phenotypes include poor iron status, growth stunting, and organ hypertrophy. Further this model agrees well with human in vitro cell line results [32-35]. In addition, the erythrocyte fatty acid composition is similar between birds and mammals [36].

Clearly, additional dietary intervention trials are needed to fully characterize the usefulness of this biomarker in relation to zinc status and zinc bioavailability over time. However, the initial results are promising as they demonstrate that dietary zinc concentration alone altered the LA:DGLA ratio, and that a significant and measurable difference for LA:DGLA was evident within the first week of 
zinc deprivation. Therefore, this ratio may be a sensitive and specific marker of zinc nutriture over an extended period of time.

Figure 4. Chicken LA:DGLA ratio of $\mathrm{Zn}(+)$ control and $\mathrm{Zn}(-)$ groups. The LA:DGLA ratio is expressed as mass percent (\% w/w). (A) Weekly chicken LA:DGLA ratio of $\mathrm{Zn}(+)$ and $\mathrm{Zn}(-)$ treatment groups $(n=12)$. ${ }^{\mathrm{a}, \mathrm{b}}$ Within a time point, means without a common letter are statistically significant $(p<0.05)$. (B) Cumulative differences in LA:DGLA ratio between $\mathrm{Zn}(+)$ control and $\mathrm{Zn}(-)$ and treatment groups $(n=12)$. ${ }^{\mathrm{a}, \mathrm{b}}$ Means without a common letter are significantly different $(p<0.001)$.

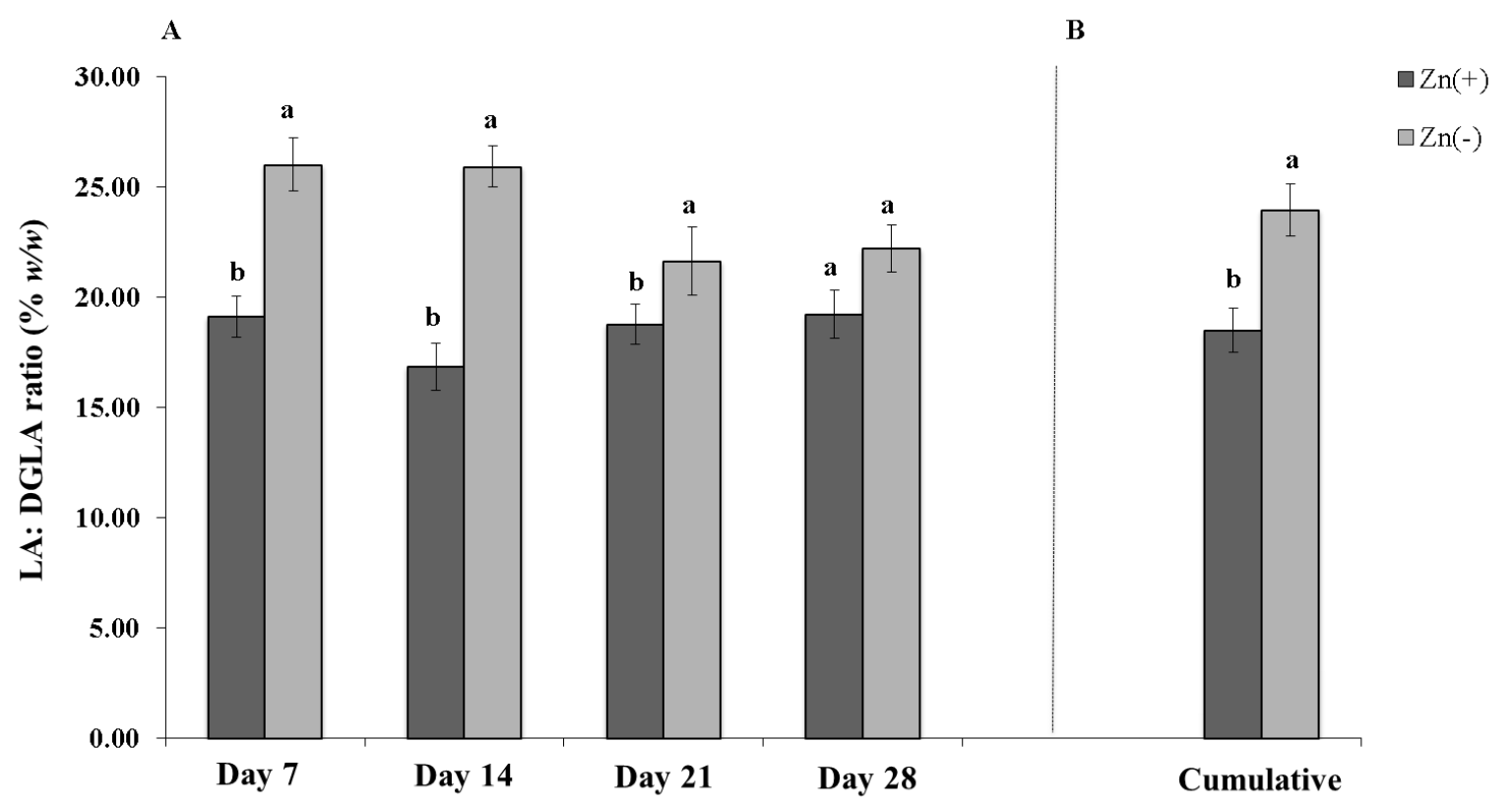

In the present study, body weight, zinc intake, and serum zinc appear to be accurate markers of zinc deficiency, as they responded to zinc depletion in a dose-dependent fashion. Feather and nail zinc concentrations seem to be efficacious biomarkers of zinc status, as well. These results are in agreement with previous studies in humans which have found serum [50,51], hair and nail zinc concentration [22,52] reflective of dietary zinc intake.

In regard to serum zinc, Lowe et al. [22] have found that factors unrelated to zinc status or depletion, such as host infection, inflammation, time of measurement, sample handling, and many other parameters may disrupt the sensitivity of serum zinc, hence its sensitivity may be inconsistent.

The relative increase in gene expression of the cytokines TNF- $\alpha$, IL- $1 \beta$, and IL- 6 in the Zn(+) group is in agreement with previous in vitro and in vivo studies where expression of various cytokines, especially TNF- $\alpha$ and IL-6, was downregulated in zinc deficient birds due to the dependency of the immune system on zinc $[53,54]$. The increase in hepatic $\Delta^{6}$ desaturase expression in the $\mathrm{Zn}(+)$ group was also expected, since zinc is an essential cofactor for the $\Delta^{6}$ desaturase enzyme. As such, zinc deficiency would impede functioning and gene expression of hepatic $\Delta^{6}$ desaturase. This observation is in accordance with previous studies [55,56].

In relation to the other zinc-related genes that were measured, previous studies have documented that even mild zinc deficiency alters many of the parameters we assessed (e.g., brush border 
enzymes [19], inflammatory cytokines [57,58], transporters and binding proteins) [59-61]. These observations are usually seen in subjects under zinc deficiency conditions and over an extended period of time. Thus, there is no question that zinc deficiency induces pathophysiological and morphological changes within the host. Rather, we suggest the possiblity that these mRNA gene expression biomarkers may not be sensitive enough to reveal differences in zinc status of deficient birds in a relativeley short feeding trial. Further, compensatory mechanisms (adaptation) by the animals to the zinc deficient diet may help to explain the lack of observational differences between many of the zinc-dependent mRNA parameters; as was previously demonstrated in vivo with the expression of DMT1 and under dietary iron deficient conditions [47]. Additional studies are required to elucidate the involvement of dietary zinc in the mechanism of action of zinc-dependent proteins and enzymes, and whether they may be responsive to dietary zinc manipulation over longer periods of time.

The results of the LA:DGLA ratio indicate that it is sensitive to changes in supplemental zinc intake. Previously, estimates by Maret et al. suggest zinc deficiency affects more than $25 \%$ of the world's population, and poses a serious risk to public health [62]. A major cause of this deficiency is believed to be insufficient dietary zinc intake [62]. However, despite such a large number of people who are affected by the pathophysiological repercussions of inadequate zinc intake, development of reliable markers to assess such deficiency is still needed $[63,64]$. Although current indices of zinc status may be able to detect relatively large differences in zinc status, most are not sensitive enough to quantify changes in and between deficient states on the basis of dietary zinc intake [64,65]. The development of sensitive zinc biomarkers, thus, is key as suggested by World Health Organization reports [65]. In the current study, our results suggest the erythrocyte LA:DGLA ratio may be a sensitive tool to investigate the effects of in vivo dietary zinc manipulation under controlled dietary and environmental conditions. Further, an additional value of this biomarker is that it can be used to assess outcomes of changing levels of dietary zinc rapidly, as demonstrated in the current study where significant differences between groups occurred within seven days. Since mild to moderate zinc deficiency does not usually present with specific organ pathologies, clinical symptoms, if present, generally go undiagnosed [63]. Hence, this biomarker could possibly be used to detect early-stage zinc deficiency before the onset of symptoms and the progression to a more serious disease state. In addition, lack of consensus surrounding the reccomendation for zinc intake stems from the difficulties in obtaining a dependable indicator of zinc status [63].

Future feeding trials are now warranted to assess LA:DGLA sensitivity in a variety of new study parameters, such as amongst treatment groups with various levels of zinc deficiency and during an extended period of time, as well as elucidate $\Delta^{6}$ desaturase kinetics. In addition, future studies may also clarify any potential LA:DGLA limitations such as whether similar effects may be observed in mammals. We suggest that the continued development of this biomarker may aid in its application as a sensitive biological indicator of zinc status.

\section{Conclusions}

This study has explored the implementation of an easily measured, potential zinc biomarker pertaining to erythrocyte fatty acid composition, the LA:DGLA ratio. These data confirm the responsiveness of the erythrocyte LA:DGLA ratio to dietary zinc manipulation. Among a panel of 
purported zinc biomarkers, this ratio appears to be sensitive to dietary zinc depletion between bird groups over time. These data serve as a justification for further feeding trials which build on our results, especially those in which a diet more representative of the target zinc-deficient population is used.

\section{Acknowledgments}

The authors wish to recognize Haim Yehuda Bar for his assistance with data analysis, Shree K. Giri for his assistance with ICP analysis, and Jung-Ho Sohn for his graphic design contributions.

\section{Conflicts of Interest}

The authors declare no conflict of interest.

\section{References}

1. Brown, K.H.; Peerson, J.M.; Rivera, J.; Allen, L.H. Effect of supplemental zinc on the growth and serum zinc concentrations of prepubertal children: A meta-analysis of randomized controlled trials. Am. J. Clin. Nutr. 2002, 75, 1062-1071.

2. King, J.C.; Cousins, R.J. Zinc. In Modern Nutrition in Health and Disease, 11th ed.; Shils, M.E., Shike, M., Ross, A.C., Caballero, B., Cousins, R.J., Eds.; Lippincott Williams \& Wilkins Press: Philadelphia, PA, USA, 2006; pp. 271-528.

3. McBean, L.D.; Dove, J.T.; Halstead, J.A.; Smith, J.C., Jr. Zinc concentration in human tissues. Am. J. Clin. Nutr. 1972, 25, 672-676.

4. Gaither, L.A.; Eide, D.J. Eukaryotic zinc transporters and their regulation. Biometals 2001, 14, 251-270.

5. Sharif, R.; Thomas, P.; Zalewski, P.; Fenech, M. The role of zinc in genomic stability. Mutat. Res. 2012, 733, 111-121.

6. Johnston, M. Genetic evidence that zinc is an essential co-factor in the DNA binding domain of GAL4 protein. Nature 1987, 328, 353-355.

7. Haase, H.; Rink, L. Signal transduction in monocytes: The role of zinc ions. Biometals 2007, 20, 579-585.

8. Prasad, A.S. Impact of the discovery of human zinc deficiency on health. J. Am. Coll. Nutr. 2009, 28, 257-265.

9. Beyersmann, D; Haase, H. Functions of zinc in signaling, proliferation and differentiation of mammalian cells. Biometals 2001, 14, 331-141.

10. Kruse-Jarres, J.D. The significance of zinc for humoral and cellular immunity. J. Trace Elem. Electrolytes Health Dis. 1989, 3, 1-8.

11. Ibs, K.H.; Rink, L. Zinc-altered immune function. J. Nutr. 2003, 133, S1452-S1456.

12. Dardenne, M. Zinc and immune function. Eur. J. Clin. Nutr. 2002, 56, S20-S23.

13. Fraker, P.J.; King, L.E.; Laakko, T.; Vollmer, T.L. The dynamic link between the integrity of the immune system and zinc status. Am. Soc. Nutr. Sci. 2000, 130, S1399-S1406. 
14. Fukada, T.; Kambe, T. Molecular and genetic features of zinc transporters in physiology and Pathogenesis. Metallomics 2001, 3, 662-674.

15. Weaver, B.P.; Dufner-Beattie, J.; Kambe, T.; Andrews, G.K. Novel zinc-responsive post-transcriptional mechanisms reciprocally regulate expression of the mouse Slc39a4 and Slc39a5 zinc transporters (Zip4 and Zip5). Biol. Chem. 2007, 388, 1301-1312.

16. Sadhu, C.; Gedamu, L. Metal-specific posttranscriptional control of human metallothionein genes. Mol. Cell. Biol. 1989, 9, 5738-5741.

17. Cousins, R.J.; Liuzzi, J.P.; Lichten, L.A. Mammalian zinc transport, trafficking, and signals. J. Biol. Chem. 2006, 281, 24085-24089.

18. Liuzzi, J.P.; Cousins, R.J. Mammalian zinc transporters. Annu. Rev. Nutr. 2004, 24, 151-172.

19. Tako, E.; Ferket, P.; Uni, Z. Changes in chicken intestinal zinc exporter mRNA expression and small intestinal functionality following intra-amniotic zinc-methionine administration. J. Nutr. Biochem. 2005, 16, 339-346.

20. Eide, D.J. The SLC39 family of metal ion transporters. Pflug. Arch. 2004, 447, 796-800.

21. Palmiter, R.D.; Huang, L. Efflux and compartmentalization of zinc by members of the SLC30 family of solute carriers. Pflug. Arch. 2004, 447, 744-751.

22. Lowe, N.M.; Fekete, K.; Decsi, T. Methods of assessment of zinc status in humans: A systematic review. Am. J. Clin. Nutr. 2009, 89, S2040-S2051.

23. Cousins, R.J. Zinc. In Present Knowledge in Nutrition, 7th ed.; Filer, L.J., Zieglerm, E.E., Eds.; International Life Sciences Institute-Nutrition Foundation Press: Washington, DC, USA, 1996; pp. 293-306.

24. Young, V.R.; Erdman, J.W.; Standing Committee on the Scientific Evaluation of Dietary Reference Intakes; Institute of Medicine (US). Zinc. In Dietary Reference Intakes for Vitamin A, Vitamin K, Boron, Chromium, Copper, Iodine, Iron, Manganese, Molybdenum, Nickel, Silicon, Vanadium, and Zinc; National Academy Press: Washington, DC, USA, 2000; pp. 442-501.

25. Thomas, E.A.; Bailey, L.B.; Kauwell, G.A.; Lee, D.Y.; Cousins, R.J. Erythrocyte metallothionein response to dietary zinc in humans. J. Nutr. 1992, 122, 2408-2414.

26. Baer, M.T.; King, J.C. Tissue zinc levels and zinc excretion during experimental zinc depletion in young men. Am. J. Clin. Nutr. 1984, 39, 556-570.

27. Ruz, M.; Cavan, K.R.; Bettger, W.J.; Gibson, R.S. Erythrocytes, erythrocyte membranes, neutrophils and platelets as biopsy materials for the assessment of zinc status in humans. Br. J. Nutr. 1992, 68, 515-527.

28. Wang, X.B.; Fosmire, G.J.; Gay, C.V.; Leach, R.M., Jr. Short-term zinc deficiency inhibits chondrocyte proliferation and induces cell apoptosis in the epiphyseal growth plate of young chickens. J. Nutr. 2002, 132, 665-673.

29. Burrell, A.L.; Dozier, W.A., III; Davis, A.J.; Compton, M.N.; Freeman, M.E.; Vendrell, P.F.; Ward, T.L. Responses of broilers to dietary zinc concentrations and sources in relation to environmental implications. Br. Poult. Sci. 2004, 45, 255-263.

30. Bao, Y.M.; Choct, M.; Iji, P.A.; Bruerton, K. Trace mineral interactions in broiler chicken diets. Br. Poult. Sci. 2010, 51, 109-117.

31. Cui, H.; Xi, P.; Junliang, D.; Debing, L.; Guang, Y. Pathology of lymphoid organs in chickens fed a diet deficient in zinc. Avian Pathol. 2004, 33, 519-524. 
32. Tako, E.; Rutzke, M.A.; Glahn, R. Using the domestic chicken (Gallus gallus) as an in vivo model for iron bioavailability. Poult. Sci. 2010, 89, 514-521.

33. Tako, E.; Glahn, R.P. White beans provide more bioavailable iron than red beans: Studies in poultry (Gallus gallus) and an in vitro digestion/Caco-2 model. Int. J. Vitam. Nutr. Res. 2010, 80, 416-429.

34. Tako, E.; Blair, M.; Glahn, R.P. Biofortified red mottled beans (Phaseolus vulgaris L.) in a maize and bean diet provide more bioavailable iron than standard red mottled beans: Studies in poultry (Gallus gallus) and an in vitro digestion/Caco-2 model. Nutr. J. 2011, 10, 113.

35. Tako, E.; Hoekenga, O.; Kochian, L.V.; Glahn, R.P. High bioavailability iron maize (Zea mays L.) developed through molecular breeding provides more absorbable iron in vitro (Caco-2 model) and in vivo (Gallus gallus). Nutr. J. 2013, 12, 3.

36. Hulbert, A.J. Explaining longevity of different animals: Is membrane fatty acid composition the missing link? Age 2008, 30, 89-97.

37. Huang, Y.S.; Cunnane, S.C.; Horrobin, D.F.; Davignon, J. Most biological effects of zinc deficiency corrected by gamma-linolenic acid (18:3 omega 6) but not by linoleic acid (18:2 omega 6). Atherosclerosis 1982, 41, 193-207.

38. Horrobin, D.F. Loss of delta-6-desaturase activity as a key factor in aging. Med. Hypotheses 1981, 7, 1211-1220.

39. Hanson, L.J.; Sorenson, D.K.; Kernkamp, H.C.H. Essential fatty acid deficiency-Its role in parakeratosis. Am. J. Vet. Res. 1958, 18, 921-930.

40. Bettger, W.J.; Reeves, P.G.; Moscatelli, E.A.; Reynolds, G.; O’Dell, B.L. Interaction of zinc and essential fatty acids in the rat. J. Nutr. 1979, 109, 480-488.

41. Cunnane, S.C. Differential regulation of essential fatty acid metabolism to the prostaglandins: Possible basis for the interaction of zinc and copper in biological systems. Prog. Lipid Res. 1982, 21, 73-90.

42. Maniongui, C.; Blond, J.P.; Ulmann, L.; Durand, G.; Poisson, J.P.; Bézard, J. Age-related changes in $\Delta 5$ and $\Delta 6$ desaturase activities in rat liver microsomes. Lipids 1993, 28, 291-297.

43. Tang, C.; Cho, H.P.; Nakamura, M.T.; Clarke, S.D. Regulation of human delta-6 desaturase gene transcription: Identification of a functional direct repeat-1 element. J. Lipid Res. 2003, 44, 686-695.

44. Sell, J.L.; Kratzer, F.H.; Latshaw, J.D.; Subcommittee on Poultry Nutrition; Committee on Animal Nutrition; Board on Agriculture; National Research Council. Nutrient Requirements of Poultry, 9th revised ed.; National Academy Press: Washington, DC, USA, 1994.

45. Mahler, G.J.; Esch, M.B.; Tako, E.; Southard, T.L.; Archer, S.D.; Glahn, R.P.; Shuler, M.L. Oral exposure to polystyrene nanoparticles affects iron absorption. Nat. Nanotechnol. 2012, 7, 264-271.

46. Tako, E.; Glahn, R.P. Iron status of the late term broiler (Gallus gallus) embryo and hatchling. Int. J. Poult. Sci. 2011, 10, 42-48.

47. Tako, E.; Glahn, R.P.; Laparra, J.M.; Welch, R.M.; Lei, X.; Kelly, J.D.; Rutzke, M.A.; Miller, D.D. Iron and zinc bioavailabilities to pigs from red and white beans (Phaseolus vulgaris L.) are similar. J. Agric. Food Chem. 2009, 57, 3134-3140. 
48. Tako, E.; Laparra, J.M.; Glahn, R.P.; Welch, R.M.; Lei, X.; Beebee, S.; Miller, D.D. Biofortified black beans in a maize and bean diet provide more bioavailable iron to piglets than standard black beans. J. Nutr. 2009, 139, 305-309.

49. Bligh, E.G.; Dyer, W.J. A rapid method of total lipid extraction and purification. Can. J. Biochem. Physiol. 1959, 37, 911-917.

50. Hess, S.Y.; Peerson, J.M.; King, J.C.; Brown, K.H. Use of serum zinc concentration as an indicator of population zinc status. Food Nutr. Bull. 2007, 28, S403-S429.

51. Swanson, C.A.; Mansourian, R.; Dirren, H.; Rapin, C.H. Zinc status of healthy elderly adults: Response to supplementation. Am. J. Clin. Nutr. 1998, 48, 343-349.

52. Chiplonkar, S.; Khadilkar, A.; Pandit-Agrawal, D.; Kawade, R.; Kadam, N.; Ekbote, V.; Sanwalka, N.; Khadilkar, V. Influence of micronutrient status and socioeconomic gradient on growth indices of 2-18-year-old Indian girls. J. Pediatr. Endocrinol. Metab. 2013, 26, 825-832.

53. Gaetke, L.M.; McClain, C.J.; Talwalkar, R.T.; Shedlofsky, S.I. Effects of endotoxin on zinc metabolism in human volunteers. Am. J. Physiol. 1997, 272, E952-E956.

54. Wieringa, F.T.; Dijkhuizen, M.A.; West, C.E.; van der Ven-Jongekrjg, J.; van der Meer, J.W.M. Reduced production of immunoregulatory cytokines in vitamin A- and zinc-deficient Indonesian infants. Eur. J. Clin. Nutr. 2004, 58, 1498-1504.

55. Koletzko, B.; Abiodun, P.O.; Laryea, M.D.; Bremer, H.J. Fatty acid composition of plasma lipids in Nigerian children with protein-energy malnutrition. Eur. J. Pediatr. 1986, 145, 109-115.

56. Ayala, S.; Brenner, R.R. Essential fatty acid status in zinc deficiency, effect on lipid and fatty acid composition, desaturation activity and structure of microsomal membranes of rat liver and testes. Acta Physiol. Lat. Am. 1983, 33, 193-204.

57. Hennig, B.; Meerarani, P.; Toborek, M.; McClain, C.J. Antioxidant-like properties of zinc in activated endothelial cells. J. Am. Coll. Nutr. 1999, 18, 152-158.

58. Beck, F.W.J.; Prasad, A.S.; Kaplan, J.; Fitzgerlad, J.T.; Brewer, G.J. Changes in cytokine production and $\mathrm{T}$ cell subpopulations in experimentally induced zinc-deficient humans. Am. J. Physiol. 1997, 272, E1002-E1007.

59. Allan, A.K.; Hawksworth, H.M.; Woodhouse, L.R.; Sutherland, B.; King, J.C.; Beattie, J.H. Lymphocyte metallothionein mRNA responds to marginal zinc intake in human volunteers. Br. J. Nutr. 2000, 84, 747-756.

60. Sullivan, V.K.; Burnett, F.R.; Cousins, R.J. Metallothionein expression is increase in monocytes and erythrocytes of young men during zinc supplementation. J. Nutr. 2000, 128, 707-713.

61. Andree, K.B.; Kim, J.; Kirschke, C.P.; Gregg, J.P.; Paik, H.; Joung, H.; Woodhouse, L.; King, J.C.; Huang, L. Investigation of lymphocyte gene expression for use as biomarkers for zinc status in humans. J. Nutr. 2004, 134, 1716-1723.

62. Maret, W.; Sandstead, H.H. Zinc requirements and the risks and benefits of zinc supplementation. J. Trace Elem. Med. Biol. 2006, 20, 3-18.

63. Gibson, R.S.; Hess, S.Y.; Hotz, C.; Brown, K.H. Indicators of zinc status at the population level: A review of the evidence. Br. J. Nutr. 2008, 99, S14-S23.

64. Hambidge, M. Biomarkers of trace mineral intake and status. J. Nutr. 2003, 133, 948S-955S. 
65. Sandstead, H.H. Zinc deficiency. A public health problem? Am. J. Dis. Child. 1991, 145, 853-859.

(C) 2014 by the authors; licensee MDPI, Basel, Switzerland. This article is an open access article distributed under the terms and conditions of the Creative Commons Attribution license (http://creativecommons.org/licenses/by/3.0/). 